\title{
Evaluation of Sleep Disorders in Chronic Obstructive Pulmonary Disease Patients by Subjective Questionnaire and Their Correlation with FEV1, $\mathrm{PaO}_{2}$, and $\mathrm{PaCO}_{2}$
}

\author{
${ }^{1}$ Sameer Vaidya, ${ }^{2}$ Ram B Sah, ${ }^{3}$ Anchal Teotiya, ${ }^{4}$ Dipti Gothi
}

\begin{abstract}
Introduction/objectives: Sleep disorders are common in chronic obstructive pulmonary disease (COPD). The commonly seen sleep disorders in COPD that can worsen the quality of sleep are insomnia, restless leg syndrome (RLS), obstructive sleep apnea (OSA), and nocturnal oxygen desaturation (NOD). However, these sleep disorders have not been studied in India.
\end{abstract}

Aim: (1) To determine the prevalence of sleep disorder in COPD patients with global sleep assessment questionnaire (GSAQ). (2) To confirm the presence of insomnia, depression, and RLS. (3) To assess the sensitivity and specificity of GSAQ with respect to insomnia, depression, and RLS. (4) Correlation of GSAQ with age, body mass index (BMI), forced expiratory volume in 1 second (FEV1), and partial pressure of arterial oxygen $\left(\mathrm{PaO}_{2}\right)$ and carbon dioxide $\left(\mathrm{PaCO}_{2}\right)$

Materials and methods: A prospective study of 60 clinically stable COPD patients was undertaken. Patients were screened for sleep disturbances with the help of the GSAQ. All participants were further assessed with the insomnia, Unpleasant Sensation, Rest induced, Gets relieved on movement, Evening (URGE), and patient health quality 4 (PHQ4) questionnaire. Spirometry and arterial blood gas $(A B G)$ analysis were done in all the patients.

Results: In the enrolled 60 patients, male:female ratio was 53:7. $33(55 \%)$ and the patients were found to have positive GSAQ. Among them, 22 (66.67.\%), 17 (57.57\%), and 23 (69.69\%) patients were suspected to have insomnia, RLS, and depression respectively. Some of them had overlap of two disorders. The overall sensitivity and specificity of GSAQ obtained by confirmatory questionnaire were 84.61 and $95.23 \%$ respectively. The difference in the mean age, $\mathrm{BMI}, \mathrm{PaO}_{2}$, and $\mathrm{PaCO}_{2}$ among GSAQ-positive and egative patients was nonsignificant $(p>0.05)$. Though low BMI was present, hypercapnea and hypoxia were more commonly present in the GSAQ-positive group. The mean FEV1 (absolute value) in GSAQ-positive group was: $1.23 \pm 0.53 \mathrm{~L} / \mathrm{min}$, while in the GSAQ-negative group, it was $1.68 \pm 0.62 \mathrm{~L} / \mathrm{min}$. The difference was statistically significant $(p-0.0003)$ for FEV1 and its low value was found correlating with high chances of sleep disorders (GSAQ positive).

Conclusion: Sleep disorders are commonly seen in COPD patients. The majority of the patients had sleep disturbance due

\footnotetext{
${ }^{1,3}$ Senior Resident, ${ }^{2}$ Medical Officer, ${ }^{4}$ Professor

${ }^{1-4}$ Department of Pulmonary Medicine, Employees' State Insurance Post Graduate Institute of Medical Sciences \& Research, New Delhi, India

Corresponding Author: Dipti Gothi, Professor, Department of Pulmonary Medicine, Employees' State Insurance Post Graduate Institute of Medical Sciences \& Research, New Delhi India, e-mail: diptigothi@gmail.com
}

to insomnia. Patients with lower FEV1 have higher chances of sleep disturbance.

Keywords: Forced vital capacity in 1 second, Global sleep assessment questionnaire, Partial pressure of arterial carbon dioxide, Partial pressure of arterial oxygen, Patient health quality 4.

How to cite this article: Vaidya S, Sah RB, Teotiya A, Gothi D. Evaluation of Sleep Disorders in Chronic Obstructive Pulmonary Disease Patients by Subjective Questionnaire and Their Correlation with FEV1, $\mathrm{PaO}_{2}$, and $\mathrm{PaCO}_{2}$. Indian J Sleep Med 2017;12(4):60-63.

\section{Source of support: Nil}

Conflict of interest: None

\section{INTRODUCTION}

Chronic obstructive pulmonary disease is one of the leading contributors to the disease burden worldwide. More than $50 \%$ of patients with COPD report significant disturbance in sleep quality. ${ }^{1}$ It has been estimated that the prevalence of sleep disturbance leading to poor quality of sleep varies from 34 to $78 \%$ in various studies. ${ }^{2-10}$ The poor quality of sleep in COPD leads to increase in mortality as well as morbidity. The GSAQ is an easy tool to screen for the prevalence of sleep disorders with a high sensitivity $>90 \%$. No study using GSAQ in COPD has been done until now.

The COPD patients have a drop in minute ventilation, reduced oxygen saturation, and elevation of $\mathrm{CO}_{2}$. Also, these patients are old and may suffer from depression, which can predispose to sleep disturbance. There is a possibility that one disorder may predispose to the other, e.g., NOD may predispose to insomnia.

The correlation of COPD severity with quality of sleep has not been clearly elucidated. There are very few reports showing the association of poor sleep quality with increased severity of $\mathrm{COPD},{ }^{9}$ while in other studies, no such occurrence has been documented. ${ }^{4,10}$ There are still gaps in the understanding of the etiologies, effects, and therapeutic measures of these sleep disorders among COPD patients.

The aims of our study were to evaluate the various sleep disorders in COPD patients by the GSAQ, its sensitivity, and specificity and to correlate poor quality of sleep detected by GSAQ with FEV1, $\mathrm{PaO}_{2}, \mathrm{PaCO}_{2}$, age, 
and BMI. Also, we need to determine the prevalence of insomnia, depression, and RLS as secondary outcomes.

\section{MATERIALS AND METHODS}

It was a prospective study that included 60 clinically stable patients. Exclusion criteria were exacerbation of COPD in the last 1 month, drug or alcohol addiction, uncontrolled systemic illness, and restrictive disorders of the thorax. All the patients were enrolled after taking written informed consent. The study was approved by the Institutional Ethic Committee. Arterial blood gas analysis and spirometry were performed in all the patients. Quality of sleep was enquired in detail with the help of the GSAQ. The GSAQ contains 11 items. It includes questions focused on determining insomnia, OSA, RLS/periodic limb movements, parasomnias, depression, and anxiety. The response to each answer is noted as "never," "sometimes," or "usually always." If the answer is "sometimes," or "usually always" to one or more of these qualities, there may be underlying sleep disorder. ${ }^{11}$

Spirometry and ABG analysis were performed in all the patients. The spirometry was performed on Morgan spirometer. The American Thoracic Society guidelines were followed for recording of forced vital capacity (FVC), FEV1, and FEV1/FVC ratio. The ABG was performed in all the patients, and $\mathrm{PaO}_{2}$ and $\mathrm{PaCO}_{2}$ were recorded in the proforma.

Insomnia, RLS, and depression were further enquired in all the patients. Defining criteria for insomnia were as per the International Classification of Sleep Disorders (ICSD). ${ }^{12}$ All the features should be present for the diagnosis. Further, patients were evaluated for RLS using the "URGE" diagnostic criteria. ${ }^{13}$ All the criteria need to be present for the diagnosis. Also, the secondary causes should be ruled out for the diagnosis. History and investigations to rule out secondary RLS were noted in detail. Depression and anxiety were assessed using the PHQ4 questionnaire, which is a four-item, ultrabrief sensitive screener. It is a 12-point scoring system ranging from 0 to 3 for each question. Questions included are: (a) feeling nervous, anxious, or on the edge; (b) not able to stop or control worrying; (c) feeling down, depressed, or hopeless; and (d) having little interest or pleasure in doing things. Scores are rated as normal (0-2), mild (3-5), moderate (6-8), and severe (9-12). Total scores $\geq 3$ for the first two questions suggest anxiety, while the same for the last two questions suggests depression. ${ }^{14}$

The data were collected and tabulated on Microsoft Excel and analyzed. Continuous data are presented as mean and standard deviation. Test of significance was done and the " $\mathrm{p}$ " value calculated. Categorical variables were tested for independence using Chi-squared test.

\section{RESULTS}

Out of the 60 patients enrolled in the study, 53 were men and 7 were women. The mean age was $60.15 \pm 8.13$ years. The age range was 34 to 73 years. The average FEV1 was $1.43 \pm 0.61$. Among the total of 60 enrolled patients, 33 (55\%) had positive GSAQ and 27 (45\%) had negative GSAQ. Among the positive GSAQs, the majority presented with insomnia, RLS, depression, and/or a combination of these. Hence, we studied insomnia, RLS, and depression further, and confirmed them using the respective questionnaire. In the given study, we could not identify the cause for disturbed sleep in six patients.

The mean age among GSAQ-positive and GSAQnegative patients were $59.45 \pm 9.63$ years and $61 \pm$ 6.07 years $(p-0.139)$ respectively. The BMI in GSAQ positive was $21.02 \pm 4.45 \mathrm{~kg} / \mathrm{m}^{2}$ and in GSAQ negative was $23.69 \pm 8.27 \mathrm{~kg} / \mathrm{m}^{2}(\mathrm{p}-0.389)$ respectively. In the GSAQ-positive group, the mean FEV1 (absolute value), $\mathrm{PaO}_{2}$, and $\mathrm{PaCO}_{2}$ were $1.23 \pm 0.53 \mathrm{~L} / \mathrm{min}, 68.66 \pm 15.93$, and $42.62 \pm 14.04 \mathrm{~mm} \mathrm{Hg}$ respectively. While in the GSAQnegative group, FEV1 (absolute value), $\mathrm{PaO}_{2}$, and $\mathrm{PaCO}_{2}$ were $1.68 \pm 0.62 \mathrm{~L} / \mathrm{min}(\mathrm{p}-0.0003), 73.62 \pm 14.22(\mathrm{p}-0.953)$ $\mathrm{mm} \mathrm{Hg}$, and $36.74 \pm 5.83(\mathrm{p}-0.7616) \mathrm{mm} \mathrm{Hg}$ respectively. The difference was statistically significant for FEV1 only; its low value was fpund correlating with high occurrences of sleep disorders (GSAQ-positive) (Table 1). Patients with lower daytime $\mathrm{PaO}_{2}$ and higher daytime $\mathrm{PaCO}_{2}$ were more frequently found to have sleep disturbances. However, the difference was not statistically significant.

Among those who were detected to have disturbed sleep as per GSAQ-positive score, 22 (36.7\%) had insomnia symptoms, 17 (51.51\%) had RLS symptoms, and $23(69.69 \%)$ had depressive symptoms. On further questioning, insomnia was confirmed in a total of $28(46.6 \%)$ patients based on insomnia questionnaire and RLS was confirmed in 19 (31.6\%) patients as per the URGE questionnaire (Table 2). Totally, 23 (38.89\%) were detected as having depression as per PHQ4. Thus, the sensitivity and specificity of GSAQ for insomnia are 78.57 and 100\%; for RLS 89.47 and $97.56 \%$; and for depression 95.65 and $88.57 \%$ respectively. The overall sensitivity and specificity of GSAQ for sleep disorders in COPD were 84.61 and $95.23 \%$ respectively.

Table 1: Values of age, BMI, FEV1 (absolute), $\mathrm{PaO}_{2}$, and $\mathrm{PaCO}_{2}$ in GSAQ-positive and -negative patients with respective "p" value

\begin{tabular}{llll}
\hline Parameter & GSAQ positive & GSAQ negative & $p$-value \\
\hline No. of patients & $33(55 \%)$ & $27(45 \%)$ & \\
Mean age (years) & $59.45 \pm 9.63$ & $61 \pm 6.07$ & -0.139 \\
$\left.\mathrm{BMI} \mathrm{(kg/m}{ }^{2}\right)$ & $20.45 \pm 3.12$ & $21.05 \pm 2.89$ & -0.389 \\
$\mathrm{FEV} 1($ Absolute) & $1.23 \pm 0.53$ & $1.68 \pm 0.62$ & -0.0003 \\
$\mathrm{PaO}_{2}$ & $68.66 \pm 15.93$ & $73.62+14.22$ & -0.953 \\
$\mathrm{PaCO}_{2}$ & $42.62 \pm 14.04$ & $38.74+5.83$ & -0.7616 \\
\hline
\end{tabular}


Table 2: The prevalence of insomnia, RLS, and depression in the study population as per GSAQ and individual questionnaire

\begin{tabular}{lll}
\hline Disorder & As per GSAQ & $\begin{array}{l}\text { As per individual } \\
\text { questionnaire }\end{array}$ \\
\hline Insomnia & $22(36.67 \%)$ & $28(46.67 \%)$ \\
RLS & $17(28.89 \%)$ & $19(31.67 \%)$ \\
Depression & $23(38.89 \%)$ & $22(36.67 \%)$ \\
\hline
\end{tabular}

\section{DISCUSSION}

Totally, 33 (55\%) patients were detected as having positive GSAQ in our study, i.e., the prevalence of sleep disturbance due to COPD was detected to be $55 \%$. Various studies have reported the disturbance varying from 34 to $78 \%{ }^{2-10}$ However, none of the studies have evaluated sleep in a structured format or holistically. Ours is the first study to evaluate sleep disorders in COPD patients in a structured format/GSAQ. We studied sleep disturbances using GSAQ, which is considered to be highly sensitive and specific. The GSAQ is a screening test, which contains 11 items. It has been shown to have variable sensitivity and specificity ${ }^{11}$ when performed for non-COPD patients. We found the sensitivity and specificity of GSAQ for insomnia: 78.57 and 100\%; for RLS: 89.47 and $97.56 \%$; and for depression: 95.65 and $88.57 \%$ respectively. The overall sensitivity and specificity was 84.61 and $95.23 \%$. Since sensitivity and specificity are close to $90 \%$, it can be administered as an initial evaluation to detect comorbid sleep disorders and, if found negative, further questioning on sleep disorders is not essential.

In our study, the mean age among GSAQ-positive and GSAQ-negative patients were $59.45 \pm 9.63$ and $61 \pm$ 6.07 years $(p-0.139)$ respectively. The patients who had poor sleep did not differ from those who had normal sleep in terms of age. The BMI in GSAQ positive was $21.02 \pm 4.45 \mathrm{~kg} / \mathrm{m}^{2}$ and GSAQ negative was $23.69 \pm 8.27$ $\mathrm{kg} / \mathrm{m}^{2}(\mathrm{p}-0.389)$. Though the difference in BMI was statistically insignificant, the BMI was lower in GSAQpositive group. Among the GSAQ-positive patients, the mean $\mathrm{PaO}_{2}$ among GSAQ positive and negative was $68.66 \pm 15.93$ and $73.62 \pm 14.22 \mathrm{~mm} \mathrm{Hg}(\mathrm{p}-0.953)$. The value of $\mathrm{PaCO}_{2}$ was high $(42.62 \pm 14.04 \mathrm{~mm} \mathrm{Hg})$ among patients who were GSAQ positive, while it was $38.74 \pm$ $5.83 \mathrm{~mm} \mathrm{Hg}$ in GSAQ negative patients ( $\mathrm{p}-0.7616)$. Our study has shown similar results for FEV1. The absolute value of FEV1 was $1.23 \pm 0.53 \mathrm{~L}$ in GSAQ-positive and $1.68 \pm 0.62$ L in GSAQ-negative groups respectively, with significant $p$-value $(p-0.0003)$. A study conducted by Budhiraja et $\mathrm{a}^{15}$ had, however, found no difference in FEV1 in patients with insomnia and without insomnia. As per our study, though the difference was significant only for FEV1, daytime lower daytime $\mathrm{PaO}_{2}$ and higher $\mathrm{PaO}_{2}$ also possibly have a direct correlation with poor quality of sleep. A larger study is required to prove the significance of daytime ABG on sleep.

Insomnia is primarily a clinical diagnosis as per the ICSD. ${ }^{12}$ Though the insomnia prevalence varies in different studies, it is definitely high in COPD patients when compared with those without COPD. ${ }^{16}$ Insomnia was the commonest sleep disturbance as per our study. In our study, the prevalence of insomnia was 28/60 (46.6\%). The study reported by Budhiraja et a ${ }^{17}$ had shown $27.5 \%$. Other studies that have focused on insomnia had reported the prevalence of insomnia in COPD ranging from 27 to $53 \%{ }^{2,18}$ So, insomnia history should be considered in all COPD patients.

Various causes of insomnia include metabolic, neurological, and psychological disorders. Among them depression, anxiety, and current tobacco use have found to be commonly associated with insomnia. ${ }^{11,19}$ We also found that the majority of the patients had insomnia due to depression and anxiety. Depression contributes to a substantial comorbidity in COPD patients. It reduces the quality of life as well as adherence to treatment. ${ }^{20}$ Hence, identifying and treating depression are important in improving quality of life. Eisner et $\mathrm{al}^{21}$ in a crosssectional study found that prevalence of depression ranges between 13 and $46 \%$ in outpatients, similar to our study, i.e., $36.67 \%$.

The second-most common cause of insomnia in our study was RLS. Totally, 19 (31.67\%) patients had sleep disturbance because of RLS. The RLS is commonly seen in COPD, but is yet an under-recognized entity. The RLS is a somatosensory network disorder with an urge to move leg and, usually, but not exclusively, affects the legs. ${ }^{19,22}$ Presence of COPD can have an additive effect on neuropsychiatric consequences of RLS. Studies have reported that 29.1 to $36.8 \%$ of the COPD patients have RLS. ${ }^{20}$ The exact mechanism by which RLS affects COPD is yet to be clearly elucidated. However, hypoxemia and/or hypercapnia have been considered as causative mechanisms for RLS. The RLS has a huge impact on quality of sleep and quality of life, in general. ${ }^{17}$ Due to poor sleep quality, RLS patients are more prone to the risk of depression, anxiety, and panic disorder. ${ }^{20}$ Thus, we found that many of our patients had overlap of two or more disorders (insomnia, anxiety, and RLS).

The exact cause of sleep disturbance could not be determined in six patients. It is possible that sleep disturbance (GSAQ positive) in these patients was due to OSA, hypoventilation, or NOD. The NOD, hypoventilation, and OSA were not studied in our patients. The other limitation of our study was a small sample size, which probably made the role of hypoxia and hypercapnea toward disturbed sleep insignificant. The frequency of occurrence of two or more sleep disorders and their 
relative contribution toward disturbed sleep could not be assessed in detail.

\section{CONCLUSION}

Sleep disorders are commonly seen in COPD patients, but remain underestimated. Insomnia is the most common sleep disorder, followed by depression and RLS. The GSAQ is an easy and specific tool to diagnose presence or absence of sleep disturbances. There is a significant correlation between patient's FEV1 and sleep quality; however, daytime ABG also seems to have a correlation with it. Regular inquiry regarding sleep in these patients by health care providers may help in improving quality of life and survival.

\section{REFERENCES}

1. American Thoracic Society. Sleep quality in COPD. New York: ATS; [cited 2017 Nov 1]. Available from: http:/ / www.thoracic. org/copd-guidelines/for-health-professionals/managementof-stable-copd/sleep/sleep-problems-in-copd.php.

2. Klink M, Quan SF. Prevalence of reported sleep disturbances in a general adult population and their relationship to obstructive airways diseases. Chest 1987 Apr;91(4):540-546.

3. Klink ME, Dodge R, Quan SF. The relation of sleep complaints to respiratory symptoms in a general population. Chest 1994 Jan;105(1):151-154.

4. Lewis CA, Fergusson W, Eaton T, Zeng I, Kolbe. Isolated nocturnal desaturation in COPD: prevalence and impact on quality of life and sleep. Thorax 2009 Feb;64(2):133-138.

5. Cormick W, Olson LG, Hensley MJ, Saunders NA. Nocturnal hypoxaemia and quality of sleep in patients with chronic obstructive lung disease. Thorax 1986 Nov;41(11):846-854.

6. Valipour A, Lavie P, Lothaller H, Mikulic I, Burghuber OC. Sleep profile and symptoms of sleep disorders in patients with stable mild to moderate chronic obstructive pulmonary disease. Sleep Med 2011 Apr;12(4):367-372.

7. Kinsman RA, Yaroush RA, Fernandez E, Dirks JF, Schocket M, Fukuhara J. Symptoms and experiences in chronic bronchitis and emphysema. Chest 1983 May;83(5):755-761.

8. Anzueto A, Ferguson GT, Feldman G, Chinsky K, Seibert A, Emmett A, Knobil K, O'Dell D, Kalberg C, Crater G. Effect of fluticasone propionate/salmeterol (250/50) on COPD exacerbations and impact on patient outcomes. COPD 2009 Oct;6(5):320-329.

9. Tashkin DP, Rennard SI, Martin P, Ramachandran S, Martin UJ, Silkoff PE, Goldman M. Efficacy and safety of budesonide and formoterol in one pressurized metered-dose inhaler in patients with moderate to very severe chronic obstructive pulmonary disease: results of a 6-month randomized clinical trial. Drugs 2008 Oct;68(14):1975-2000.

10. Price D, Small M, Milligan G, Higgins V, Gil EG, Estruch J. The prevalence and impact of nighttime symptoms in COPD patients-a real-world study in five European countries. Int J Chron Obstruct Pulmon Dis 2013 Nov;8:595-603.

11. Roth T, Zammit G, Kushida C, Doghramji K, Mathias SD, Wong JM, Buysse DJ. A new questionnaire to detect sleep disorders. Sleep Med 2002 Mar;3(2):99-108.

12. American Association of Sleep Medicine. International classification of sleep disorders. 3rd ed. Darien (IL): American Association of Sleep Medicine; 2014.

13. International Restless Legs Study Group. IRLSSG diagnostic criteria for RLS. Rochester (MN): IRLSSG; 2012. [cited 2012 Jun 7]. Available from: www.irlssg.org.

14. Kroenke K, Spitzer RL, Williams JB, Lowe B. An ultra brief screening scale for anxiety and depression : the PHQ-4. Psychosomatics 2009 Nov-Dec;50(6):613-621.

15. Budhiraja R, Parthasarathy S, Budhiraja P, Habib MP, Wendel C, Quan SF. Insomnia in patients with COPD. Sleep 2012 Mar;35(3):369-375.

16. Fleetham J, West P, Mezon B, Conway W, Roth T, Kryger M. Sleep, arousals, and oxygen desaturation in chronic obstructive pulmonary disease. The effect of oxygen therapy. Am Rev Respir Dis 1982 Sep;126(3):429-433.

17. Budhiraja R, Siddiqi TA, Quan SF. Sleep disorders in chronic obstructive pulmonary disease: etiology, impact, and management. J Clin Sleep Med 2015 Mar;11(3):259-270.

18. Lacasse $\mathrm{Y}$, Sériès F, Vujovic-Zotovic N, Goldstein R, Bourbeau J, Lecours R, Aaron SD, Maltais F. Evaluating nocturnal oxygen desaturation in COPD revised. Respir Med 2011 Sep;105(9):1331-1337.

19. Aras G, Kadakal F, Purisa S, Kanmaz D, Aynaci A, Isik E. Are we aware of restless legs syndrome in COPD patients who are in an exacerbation period? Frequency and probable factors related to underlying mechanism. COPD 2011 Dec;8(6): 437-443.

20. Innes KE, Selfe TK, Agarwal P. Restless legs syndrome and conditions associated with metabolic dysregulation, sympathoadrenal dysfunction, and cardiovascular disease risk: a systematic review. Sleep Med Rev 2012 Aug;16(4):309-339.

21. Eisner MD, Blanc PD, Yelin EH, Katz PP, Sanchez G, Iribarren C, Omachi TA. Influence of anxiety on health outcomes in COPD. Thorax 2010 Mar;65(3):229-234.

22. Gothi D. Restless legs syndrome: common yet an under recognized entity. Indian J Sleep Med 2014;9(2):41-49. 